\title{
An outer-membrane porin inducible by short- chain amides and urea in the methylotrophic bacterium Methylophilus methylotrophus
}

\author{
James Mills, $\uparrow$ Neil R. Wyborn, $\neq$ Jacqueline A. Greenwood, \\ Steven G. Williams $\$ \&$ Colin W. Jones
}

Department of

Biochemistry, University of

Leicester, Leicester

LE1 7RH, UK

\author{
Author for correspondence: Colin W. Jones. Tel: +441162523 458. Fax: +441162523369. \\ e-mail: cwj1@le.ac.uk
}

The fmd $A$ and $f m d B$ genes encoding formamidase and a putative regulatory protein, respectively, from the methylotrophic bacterium Methylophilus methylotrophus were recloned with additional flanking DNA (pSW1). fmdC, encoding a weakly hydrophilic protein containing an $\mathbf{N}$-terminal signal sequence, was identified upstream of fmdAB. The derived amino acid sequence of mature FmdC $\left(M_{\mathrm{r}} 39204\right)$ showed that it was rich in $\beta$-sheet and aromatic amino acids, and exhibited significant similarities to several outer-membrane porins from other bacteria. Cell fractionation studies showed that the protein was located in the outer membrane. Mature FmdC was purified and shown to consist of a single type of subunit $\left(M_{\mathrm{r}} 40000\right)$ with the predicted $N$-terminal amino acid sequence (GATISF-). SDS-PAGE and Western blotting of cells grown in continuous culture under various conditions showed that mature FmdC was induced by formamide, acetamide and urea, repressed by excess ammonia, and over-expressed during prolonged growth under formamide limitation. It is concluded that mature FmdC is a porin involved in the transport of short-chain amides and urea through the outer membrane of $M$. methylotrophus under conditions where these nitrogen sources are present at very low concentration.

Keywords: Methylophilus methylotrophus, outer-membrane porin, amide-urea porin, fmdC gene

\section{INTRODUCTION}

The methylotrophic bacterium Methylophilus methylotrophus readily uses formamide as a source of nitrogen for growth by virtue of its ability to hydrolyse the amide to ammonia and formate using a cytoplasmic formamidase (formamide amidohydrolase; EC 3.5.1.49). The purified enzyme exhibits a high activity with formamide, very low activity with short-chain aliphatic amides and no activity with urea (Wyborn et al., 1994).

\footnotetext{
†Present address: Cantab Pharmaceuticals Research Ltd, Cambridge Science Park, Cambridge CB4 4GN, UK.

¥Present address: Department of Molecular Biology and Biotechnology, University of Sheffield, Sheffield S10 2TN, UK.

SPresent address: Therexsys, The Science Park, University of Keele, Keele, Staffs ST5 5SP, UK.

The EMBL accession number for the sequence reported in this paper is Y12064.
}

Nucleotide sequencing of a $2.3 \mathrm{kbp}$ HindIII-PstI restriction fragment of $M$. methylotrophus DNA ( $\mathrm{pNW} 323$ ) has shown the presence of two genes, fmdA and $f m d B$, which encode formamidase and a putative positive regulator, respectively; these genes probably comprise an operon which is transcribed in the direction fmdAB (Wyborn et al., 1996). M. methylotrophus formamidase (FmdA) is closely related on the basis of its derived amino acid sequence, secondary structure and immunological properties to the formamidase (acetamidase) from Mycobacterium smegmatis (Mahenthiralingam et al., 1993; Wyborn et al., 1996).

The location of the M. methylotrophus formamidase in the cytoplasm of the cell implies that formamide must traverse both the outer and inner membranes prior to hydrolysis. In principle, passage through the outer membrane could occur either unmediated (simple diffusion) or via the mediation of a membrane protein (facilitated diffusion). Porin-mediated facilitated dif- 
fusion of molecules such as sugars, sugar acids, phosphate and various cations through bacterial outer membranes is well documented (Nikaido, 1993, 1994; Schulz, 1993). In contrast, very small uncharged molecules such as formamide can pass freely through the outer membrane by simple diffusion when present at high concentrations, but little is known about the movement of such molecules under conditions when they are limiting for growth. No porins have as yet been identified in methylotrophic bacteria, but the ability of $M$. methylotrophus to use a very low steady-state concentration $(<50 \mu \mathrm{M})$ of formamide $\left(M_{\mathrm{r}} 45\right)$ or urea $\left(M_{r} 60\right)$ as a source of nitrogen during growth in continuous culture under formamide or urea limitation (J. Mills \& C. W. Jones, unpublished) suggests that a porin(s) may be present for these substrates.

In this paper we report the characterization of the $f m d C$ gene encoding an outer-membrane porin ( $\mathrm{FmdC}$ ) in $M$. methylotrophus, the purification and partial characterization of the porin, and the physiological regulation of the porin expression by short-chain amides and urea.

\section{METHODS}

Bacterial strains and plasmids. The bacterial strains used in this work were Methylophilus methylotrophus (NCIMB 10515), Escherichia coli JM109 [recA1 supE44 endA1 hsdR17 gyrA96 $\mathrm{F}^{\prime}$ (traD36 proAB lacl $^{\mathrm{q}}$ lacZ $\Delta \mathrm{M} 15$ ) relA1 thi $\Delta$ (lacproAB)] and E. coli NM522 [supE hsd5 $\mathrm{F}^{\prime}$ (proAB ${ }^{+}$lacI $^{\mathrm{a}}$ lac $Z \Delta M 15)$ thi $\Delta$ (lac-pro $A B)]$. The plasmids used in this work were pUC18, pUC19 (amp lac $Z^{\prime}$ ), pNW3 and pNW323 (pUC19 carrying respectively a $3.2 \mathrm{kbp}$ PstI restriction fragment and a $2.3 \mathrm{kbp}$ HindIII-PstI restriction fragment of $M$. methylotrophus DNA; Wyborn et al., 1994, 1996), and pSW1 (pUC18 carrying an $8.4 \mathrm{kbp} S p h I$ restriction fragment of $M$. methylotrophus DNA).

Growth of bacteria. M. methylotrophus was grown in continuous culture (dilution rate, $D, 0 \cdot 1 \mathrm{~h}^{-1}$ ) in methanolmineral salts medium at $37^{\circ} \mathrm{C}$ with ammonia, formamide, acetamide or urea as the source of nitrogen (Wyborn et al., 1994). E. coli was grown in batch culture in M9 glucosemineral salts liquid medium at $37^{\circ} \mathrm{C}$ with $20 \mathrm{mM}$ ammonia, formamide or acetamide as the source of nitrogen (Sambrook et al., 1989; Wyborn et al., 1994); during the growth of clones carrying pUC18/19 or derivatives of pUC18/19, all media were supplemented with ampicillin $\left(50 \mu \mathrm{g} \mathrm{ml}^{-1}\right)$. Culture supernatants were prepared by centrifuging samples for $1 \mathrm{~min}$ at maximum speed in an MSE MicroCentaur bench-top centrifuge; the concentration of ammonia in the supernatants was measured colorimetrically (Silman et al., 1989).

Preparation of washed cells and measurement of formamidase activity. Washed cells were prepared and assayed for formamidase activity as described previously (Silman et al., 1989; Wyborn et al., 1994).

Preparation of crude membrane and high-speed supernatant fractions. A formamide-limited continuous culture of $M$. methylotrophus $\left(D 0 \cdot 1 \mathrm{~h}^{-1}\right)$ was harvested by centrifugation at $12200 \mathrm{~g}$ for $15 \mathrm{~min}$, then washed in $50 \mathrm{mM}$ Tris/ $\mathrm{HCl}$ buffer $\mathrm{pH} 7 \cdot 5$, re-centrifuged and resuspended finally in the same buffer to a cell density of $40-50 \mathrm{mg}$ dry wt $\mathrm{ml}^{-1}$. The cell suspension was disrupted by passage three times through an
Aminco French pressure cell at approximately 9.0 MPa, then unbroken cells and cell debris were removed by centrifugation at $40000 \mathrm{~g}$ for $20 \mathrm{~min}$ to produce a cell-free extract. The latter was centrifuged at $175000 \mathrm{~g}$ for $75 \mathrm{~min}$ to produce a highspeed supernatant fraction, which was removed carefully with a Pasteur pipette, and a crude membrane fraction which was washed by re-centrifugation in $50 \mathrm{mM}$ Tris/ $\mathrm{HCl}$ buffer $\mathrm{pH} 7 \cdot 5$ and resuspended finally in the same buffer to approximately $30 \mathrm{mg}$ protein $\mathrm{ml}^{-1}$. The crude membrane and high-speed supernatant fractions were stored at $-20^{\circ} \mathrm{C}$ until required. Protein was assayed by the method of Bradford (1976) using the Bio-Rad protein assay reagent.

Purification of mature FmdC. The crude membrane fraction, diluted to $3 \mathrm{mg}$ protein $\mathrm{ml}^{-1}$ in $50 \mathrm{mM}$ Tris/HCl buffer $\mathrm{pH} 7 \cdot 5$ plus $5 \mathrm{mM}$ EDTA and $1 \%(\mathrm{w} / \mathrm{v}) \mathrm{N}$-lauroyl sarcosine, was stirred on ice for $30 \mathrm{~min}$ and then centrifuged at $120000 \mathrm{~g}$ for $1 \mathrm{~h}$. The resultant outer-membrane pellet was resuspended in $50 \mathrm{mM}$ Tris/ $\mathrm{HCl}$ buffer $\mathrm{pH} 7 \cdot 5$ plus $4 \%$ (w/v) Triton $\mathrm{X}-100$, then centrifuged at $120000 \mathrm{~g}$ for $1 \mathrm{~h}$. The supernatant containing solubilized outer membrane was dialysed overnight at $4{ }^{\circ} \mathrm{C}$ in $50 \mathrm{mM}$ Tris/ $\mathrm{HCl}$ buffer $\mathrm{pH} 7.5$ plus $0.1 \%(\mathrm{w} / \mathrm{v})$ Triton X-100 to decrease the concentration of the detergent, then filtered through an acrodisc filter $\langle 0.2 \mu \mathrm{m}$ pore size; Gelman), loaded on to an FPLC Mono-Q 5/5 anion-exchange column (Pharmacia) and eluted via a linear gradient of $0-1 \mathrm{M}$ $\mathrm{NaCl}$ in the same buffer at a flow rate of $2 \mathrm{ml} \mathrm{min}^{-1}$ over 10 column volumes. Mature FmdC eluted at approximately $120 \mathrm{mM} \mathrm{NaCl}$. Peak fractions were bulked, then concentrated and de-salted using an Omegacell unit containing an $M_{r} 10000$ cut-off filter (Flowgen). The protein was shown subsequently by SDS-PAGE to be $\geqslant 95 \%$ pure.

Preparation of antiserum to mature FmdC. Antiserum to purified, mature FmdC was prepared essentially as described previously for antiserum to formamidase (Wyborn et al., 1996), but using two rats rather than a rabbit. The antiserum was stored at $-20^{\circ} \mathrm{C}$ until required.

PAGE. Discontinuous SDS-PAGE was carried out as described previously (Silman et al., 1989) and gels were stained for protein with Kenacid blue R. Western blotting was carried out as described previously (Greenwood et al., 1990), but using antiserum to mature FmdC.

$\mathrm{N}$-terminal amino acid sequencing. $\mathrm{N}$-terminal amino acid sequencing of proteins excised from polyacrylamide gels was carried out using an Applied Biosystems model 470 gas-phase sequencer as described previously (Wyborn et al., 1996).

DNA sequencing and analysis. Double-stranded plasmid DNA was isolated and sequenced as described previously (Wyborn et al., 1996). Nucleotide and derived amino acid sequence analyses were carried out using DNA Strider version 1.2, and the University of Wisconsin Genetics Computer Group sequence analysis package version 8.0 (BLAST, CODONPREFERENCE, GAP, ISOELECTRIC and MOTIFS programs). Secondary structure predictions were obtained using the PHD program (Rost \& Sander, 1993, 1994) and the turn-prediction rules for $\beta$-sheet proteins (Jeanteur et al., 1991).

Chemicals and enzymes. Restriction endonucleases and T4 ligase were obtained from BRL; calf intestinal phosphatase was obtained from Pharmacia. Protein $M_{r}$ standards were obtained from Sigma. All other chemicals used were obtained from Fisons or Sigma, and were of the highest grade obtainable.

Presentation of results. Results are expressed, where ap- 
propriate, as the mean \pm SEM with the number of independent determinations given in parentheses.

\section{RESULTS AND DISCUSSION}

\section{Construction and characterization of pSW1}

Nucleotide sequencing of a $2.3 \mathrm{kbp}$ HindIII-PstI fragment of $M$. methylotrophus DNA in pNW323 (a subclone of $\mathrm{pNW} 3$ ) had previously shown the presence of $f m d A$ and $f m d B$ encoding formamidase and a putative positive regulator, respectively (Wyborn et al., 1996). To investigate flanking genes, an $8.4 \mathrm{kbp} \mathrm{SphI-fragment} \mathrm{of}$ M. methylotrophus chromosomal DNA likely to contain these genes was identified by Southern blotting using the pNW3 insert as a probe, then cloned in pUC18 to generate pSW1 essentially as described previously for pNW3 (Wyborn et al., 1996). Restriction analysis of pSW1 showed that it contained insert DNA identical to that in pNW3 plus $5.2 \mathrm{kbp}$ of additional flanking DNA (2.5 kbp upstream and $2.7 \mathrm{kbp}$ downstream) (Fig. 1a).

E. coli NM522(pSW1) exhibited a similar phenotype to that of E. coli JM109(pNW3) and JM109(pNW323) (Wyborn et al., 1994, 1996) viz. (i) growth on glucosemineral salts medium supplemented with formamide or acetamide as nitrogen source, and (ii) synthesis of formamidase as determined by measurement of formamidase activity and concentration (SDS-PAGE and Western blotting using antiserum to formamidase). SDSPAGE also showed the presence in NM522(pSW1) of a protein(s) of $M_{\mathrm{r}} 40000$ which was absent from JM109(pNW3) and JM109(pNW323). Neither of the control strains, E. coli JM109(pUC19) and NM522 (pUC18), grew on glucose-mineral salts medium supplemented with either formamide or acetamide as nitrogen source, or synthesized either formamidase or the $M_{\mathrm{r}}$ 40000 protein(s). It was concluded that the $8.4 \mathrm{kbp}$ insert

(a)

$\longleftarrow 1.0 \mathrm{kbp}$
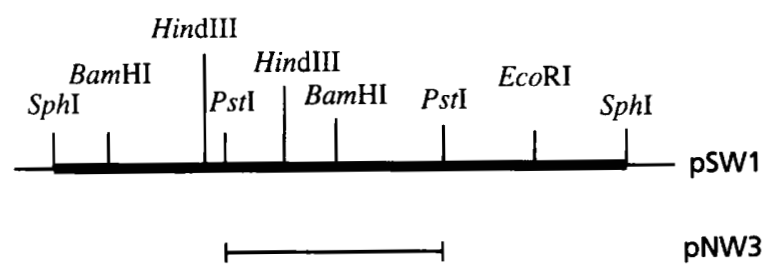

pNW3

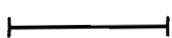

pNW323

(b)

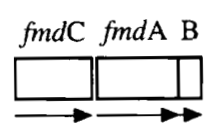

Fig. 1. Restriction mapping and genetic organization of part of the $8.4 \mathrm{kbp} S p h$-restriction fragment of $M$. methylotrophus DNA in pSW1. (a) Restriction map and plasmids; (b) organization of the fmd genes. in pSW1 contains $f m d A B$ plus an additional gene(s) encoding a protein(s) of $M_{\mathrm{r}}$ approximately 40000 .

\section{Nucleotide sequence of $\mathrm{fmdC}$}

The $8.4 \mathrm{kbp}$ insert in pSW1 was sequenced in both directions for approximately $1.4 \mathrm{kbp}$ upstream of $f m d A$. Codon preference analysis showed the presence of an ORF (orfC, later identified as $f m d C$; Fig. 1 b) which was preceded by a putative ribosome-binding site (RBS). Several potential ORFs were identified on the opposite strand of the DNA, but none of these encoded proteins of $M_{\mathrm{r}}>5000$ or were preceded by a candidate RBS.

fmdC contained $1170 \mathrm{bp}$ and was preceded by a potential RBS (GGGAGT) centred eight nucleotides upstream of the ATG translational start codon (taken to be the first of two successive ATG codons). The presumptive RBS was similar to the consensus sequences found in E. coli (AGGAGG) and various methylotrophic bacteria, including Methylophilus spp. (AGGAGA) (see Wyborn et al., 1996), and was preceded by putative '-24' (CTGGCT)/'-12' (TTGCTT) promoter sequences centred 240 and 228 nucleotides, respectively, upstream of the translational start site. These sequences conformed to the consensus nitrogen-regulated '- -24 '/ ' -12 ' promoter sequence (GG-N ${ }_{10}-\mathrm{GC}$ ) found upstream of various genes in Klebsiella pneumoniae and Salmonella typhimurium (Dixon, 1984; Merrick, 1988), of amiC in Pseudomonas aeruginosa (Wilson \& Drew, 1991) and of fmdA in M. methylotrophus (Wyborn et al., 1996). No potential promoter sequences similar to the canonical ' $-35^{\prime} \%$ ' 10 ' sequences found in E. coli (TTGACA and TATAAT) and various methylotrophic bacteria, including Methylophilus spp. (TTGACC and TATAAT) (see Wyborn et al., 1996) were identified upstream of $f m d C$. $f m d C$ was terminated by a TAA translational stop codon centred 43 nucleotides upstream of the ATG translational start codon of $f m d A$. The derived amino acid sequence showed that $f m d C$ encodes a protein of 390 amino acids with a predicted $M_{\mathrm{r}}$ of 41817 .

\section{Analysis of predicted amino acid sequence of FmdC}

In an attempt to identify FmdC, washed cells were prepared from a formamide-limited continuous culture (D $0.1 \mathrm{~h}^{-1}$ ) of $M$. methylotrophus and cell proteins were separated by SDS-PAGE. A strongly expressed protein(s) of $M_{\mathrm{r}}$ approximately 40000 was then excised and subjected to $\mathrm{N}$-terminal amino acid sequencing. This revealed two sequences (GATISF- and ADYPTA-), suggesting the presence of two proteins in approximately equal concentrations. The sequence GATISF- was identical to residues $27-32$ in the derived amino acid sequence of $\mathrm{FmdC}$, indicating that the mature protein was produced by removal of a 26 amino acid signal peptide (MMNLKKCALHTAVAMACGLGAQLANA). The latter exhibited the expected characteristics of a prokaryotic signal sequence (see Duffaud et al., 1985; Goodwin \& Anthony, 1995), viz. a basic N-terminal 


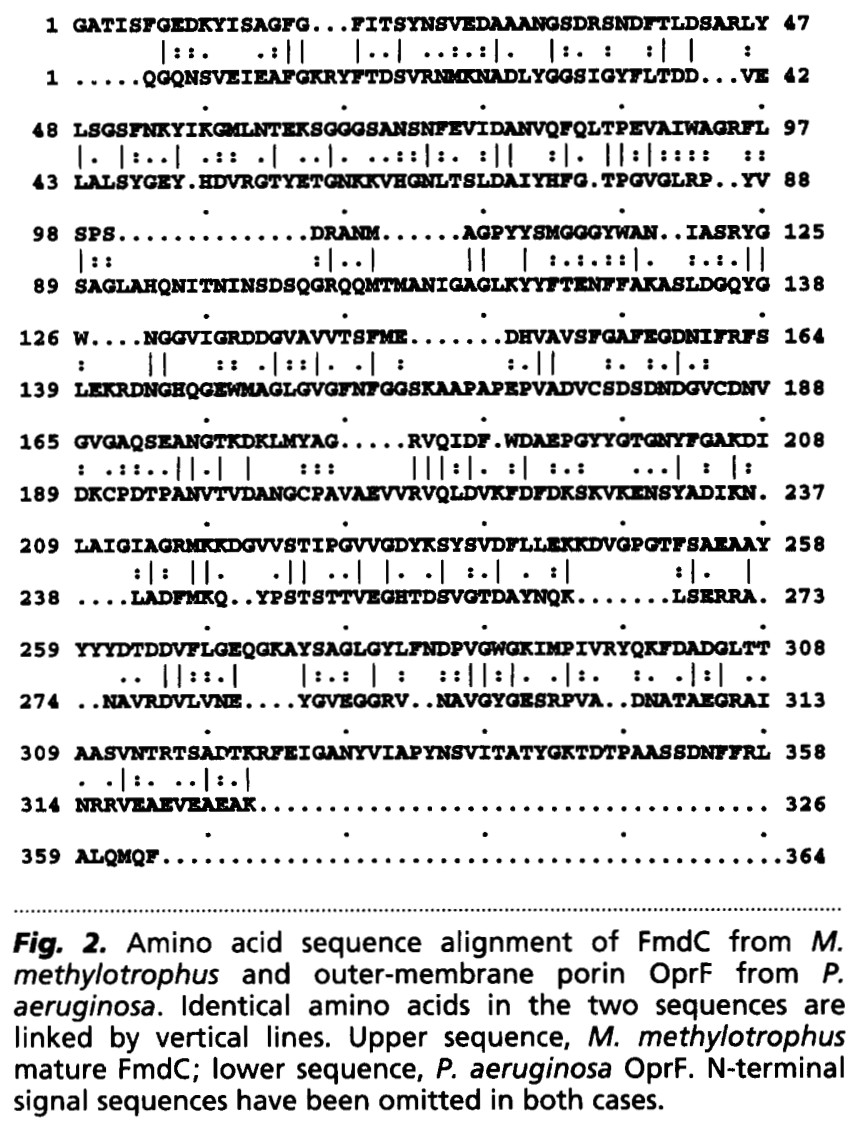

region (two adjacent lysine residues, no acidic residues), a central region of high hydrophobicity (as evidenced by a hydropathy profile of FmdC based on Kyte-Doolittle assignments; Kyte \& Doolittle, 1982; not shown), a Cterminal domain containing a helix-disrupting glycine residue, and an AxA sequence immediately upstream of the cleavage site.

Analysis of the derived amino acid sequence of mature FmdC revealed an overall hydropathy index of $-0 \cdot 2$, an isoelectric point of 4.53 , a net charge of -10.5 , and an unusually high content $(14.6 \%)$ of aromatic amino acids (Phe, Tryp and Tyr). It was concluded that mature FmdC is a weakly hydrophilic, acidic protein composed of 364 amino acids with a predicted $M_{\mathrm{r}}$ of 39204 .

Comparison of the derived amino acid sequence of mature FmdC with other proteins in the databases revealed significant similarities to several outer-membrane porins, viz. $P$. aeruginosa $\mathrm{OprF}(26 \cdot 2 \%$ identical, $52.1 \%$ similar including conservative replacements) (Fig. 2), E. coli OmpF (23.3\% identical, $49.0 \%$ similar) and the Rhodopseudomonas blastica porin $(20.6 \%$ identical, 48.8\% similar) (Duchene et al., 1988; Cowan et al., 1992; Kreusch \& Schulz, 1994). Weaker similarities were observed with the Rhodobacter capsulatus porin, E. coli OmpA and PhoE, and P. aeruginosa OprD. Furthermore, the presence of phenylalanine as the Cterminal amino acid in $\mathrm{FmdC}$ is characteristic of many outer-membrane porins (but not OprF), as also is the high content of aromatic amino acids and the overall

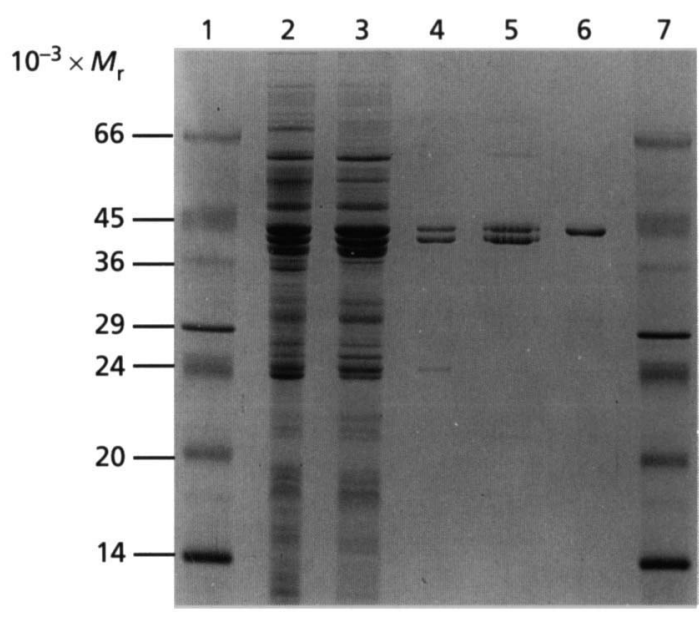

Fig. 3. Purification of mature FmdC. Samples taken from each stage of the purification procedure were subjected to SDS-PAGE and stained for protein. Tracks: 1, $M_{r}$ standards; 2, washed cells; 3, crude membrane fraction; 4, outer membranes; 5 , Triton-solubilized outer membranes; 6, purified mature FmdC; 7, $M_{\mathrm{r}}$ standards.

negative charge (Struyve et al., 1991; Nieweg \& Bremer 1997).

Secondary structure predictions (Jeanteur et al., 1991; Rost \& Sander, 1993, 1994) showed that mature FmdC was particularly rich in $\beta$-sheet (37\% $\beta$-sheet cf. $20 \% \alpha$ helix) and contained at least 14 putative membranespanning $\beta$-strands. Other porins have also been shown to have a high $\beta$-sheet content and up to $18 \beta$-strands, commensurate with their proposed antiparallel $\beta$-barrel structures (Cowan et al., 1992; Nikaido, 1993, 1994; Schulz, 1993; Kreusch \& Schulz, 1994; Rawling et al., 1995; Schirmer et al., 1995; Nieweg \& Bremer 1997).

Analysis of subcellular fractions of $M$. methylotrophus showed that mature FmdC (identified using SDS-PAGE followed by $\mathrm{N}$-terminal amino acid sequencing of the $M_{\mathrm{r}} 40000$ protein(s) or Western blotting using antiserum prepared against the purified protein; see below) was one of two major proteins located in the outermembrane. The identities of the second outer-membrane protein $\left(M_{r}\right.$ approximately 38000$)$ and the other $M_{r}$ 40000 protein (ADYPTA-; not located in the outer membrane) are currently under investigation.

In view of its cellular location, derived amino acid composition and sequence, and predicted secondary structure, mature FmdC was tentatively identified as an outer-membrane porin.

\section{Purification of mature FmdC}

Mature FmdC was purified from a formamide-limited continuous culture of M. methylotrophus (Fig. 3). The purified protein was shown by SDS-PAGE to be $\geqslant 95 \%$ pure, and by $\mathrm{N}$-terminal amino acid sequencing to contain the predicted $\mathrm{N}$-terminal sequence (GATISF-). SDS-PAGE yielded a subunit $M_{r}$ of approximately 
Table 1. Physiological regulation of formamidase and mature FmdC expression in M. methylotrophus

M. methylotrophus was grown in continuous culture $\left(D 0 \cdot 1 \mathrm{~h}^{-1}\right)$ under various nutrient limitations with methanol as the carbon source and ammonia, formamide, acetamide or urea as the nitrogen source. Formamidase activities were measured colorimetrically; formamidase and mature FmdC concentrations were determined semi-quantitatively by SDS-PAGE and Western blotting. Formamidase activities $\left[\mu \mathrm{mol} \mathrm{min}{ }^{-1}(\mathrm{mg} \text { cells })^{-1}\right]$ are expressed as mean $\pm \mathrm{SEM}$ (number of independent determinations).

\begin{tabular}{|c|c|c|c|c|c|}
\hline \multirow[t]{2}{*}{$\mathrm{N}$-source } & \multirow{2}{*}{$\begin{array}{l}\text { Limiting } \\
\text { nutrient }\end{array}$} & \multirow{2}{*}{$\begin{array}{c}\text { [Ammonia] } \\
(\mathrm{mM})\end{array}$} & \multicolumn{2}{|c|}{ Formamidase } & \multirow{2}{*}{$\begin{array}{c}\text { Mature } \\
\text { FmdC concn }\end{array}$} \\
\hline & & & Activity & Concn & \\
\hline \multirow[t]{2}{*}{ Ammonia } & Ammonia & $<0.05$ & $0.29 \pm 0.14(6)$ & - & - \\
\hline & Methanol & $5 \cdot 90$ & $0.02 \pm 0.02(3)$ & + & - \\
\hline \multirow[t]{2}{*}{ Formamide } & Formamide & $<0.05$ & $2.64 \pm 0.31(7)$ & $++t$ & ++ \\
\hline & Methanol & 8.90 & $0 \cdot 23(2)$ & + & - \\
\hline \multirow[t]{2}{*}{ Acetamide } & Acetamide & $<0.05$ & $1.37 \pm 0.35(4)$ & +++ & ++ \\
\hline & Methanol & $7 \cdot 00$ & $0 \cdot 19(2)$ & + & - \\
\hline \multirow[t]{2}{*}{ Urea } & Urea & $<0.05$ & $3 \cdot 39(2)$ & +++ & ++ \\
\hline & Methanol & 1.80 & $0.08(2)$ & + & - \\
\hline
\end{tabular}

(a)

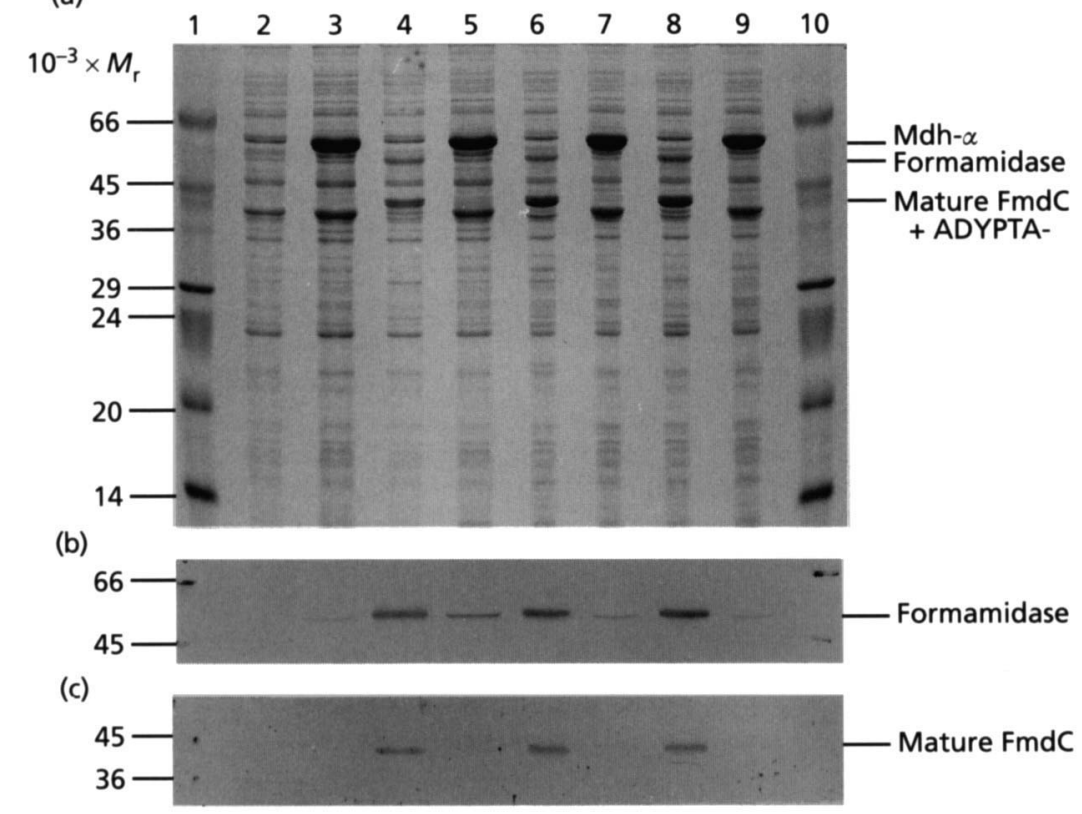

Fig. 4. Physiological regulation of formamidase and mature FmdC expression in $M$. methylotrophus. $M$. methylotrophus was grown in continuous culture $\left(D 0.1 \mathrm{~h}^{-1}\right)$ under various nutrient limitations. Cells were harvested and cell proteins separated by SDS-PAGE (a), then transferred to nitrocellulose and probed with antiserum to formamidase (b) or mature FmdC (c). Tracks: 1, $M_{\mathrm{r}}$ standards; 2, ammonia-limited; 3, methanol-limited (ammonia excess); 4, acetamide-limited; 5, methanol-limited (acetamide excess); 6, formamide-limited; 7, methanol-limited (formamide excess); 8, urea-limited; 9, methanol-limited (urea excess); $10, M_{r}$ standards. Formamidase runs anomalously on SDS-polyacrylamide gels, giving a subunit $M_{\mathrm{r}}$ of 51000 compared with a predicted $M_{r}$ of only 44438 from the nucleotide sequence of fmdA (Wyborn et al., 1994, 1996). Mdh- $\alpha, \alpha$-subunit of methanol dehydrogenase.
40000 (cf. 39204 from the derived amino acid sequence) which increased to approximately 75000 when the protein was pre-treated with SDS at $30^{\circ} \mathrm{C}$ instead of the normal $100^{\circ} \mathrm{C}$ (behaviour chracteristic of many outermembrane porins). SDS-PAGE and Western blotting using antiserum raised against the purified porin showed that it cross-reacted strongly against its own antigen, but not against the other other $M_{\mathrm{r}} 40000$ protein (ADYPTA-) or the second outer-membrane protein.

\section{Physiological regulation of formamidase and porin expression}

M. methylotrophus was grown in continuous culture $(D$ $0 \cdot 10 \mathrm{~h}^{-1}$ ) under various nutrient limitations with methanol as the carbon source and either ammonia, formamide, acetamide or urea as the nitrogen source. Formamidase activities were highest during growth under amide or urea limitation, and were greatly diminished 
during growth under methanol limitation (i.e. in the presence of a high concentration of ammonia resulting either from its direct addition or from the hydrolysis of excess amides or urea) (Table 1). These variations in formamidase activity were accompanied by similar variations in formamidase concentration as determined by SDS-PAGE and Western blotting using antiserum to formamidase (Fig. 4a, b). The combined concentrations of the $M_{\mathrm{r}} 40000$ proteins (mature FmdC and ADYPTA) followed a similar pattern to that of formamidase, and this was confirmed for mature FmdC by Western blotting (Fig. 4c); the antiserum also cross-reacted with an unidentified protein $\left(M_{\mathrm{r}} 22000\right)$, the concentration of which was unaffected by the growth conditions (not shown). Both formamidase and mature FmdC were therefore induced strongly by amides and urea, and repressed by a high concentration of ammonia.

\section{Over-expression of the porin during prolonged growth under formamide limitation}

M. methylotrophus was grown for 308 generations $(89 \mathrm{~d})$ in formamide-limited continuous culture (D $\left.0 \cdot 1 \mathrm{~h}^{-1}\right)$. SDS-PAGE of washed cells showed that the concentration of formamidase remained essentially constant over the course of the experiment, whereas the combined concentrations of the $M_{\mathrm{r}} 40000$ proteins (mature FmdC and ADYPTA-) remained constant for at least 66 generations and then approximately doubled. This pattern was confirmed for the porin by Western blotting using antiserum to mature FmdC. In contrast, the concentration of methanol dehydrogenase ( $\alpha$-subunit, $M_{\mathrm{r}} 60000$ ) decreased over the first 66 generations and then levelled off, and the concentrations of several other strongly expressed proteins $\left(M_{\mathrm{r}} 67000,47000\right.$ and 22000) remained essentially constant over the entire experiment.

\section{Role of porin A during the growth of M. methylotrophus}

The probable role of mature FmdC during the growth of M. methylotrophus is to facilitate the passage of shortchain amides (e.g. formamide, acetamide) and urea into the periplasm when the concentrations of these compounds in the surrounding medium are extremely low. Simple considerations of solute diffusion rates at very low external concentrations highlight the requirement of micro-organisms to synthesize appropriate porins under these conditions (Nikaido \& Vaara, 1985), even for small uncharged substrates such as formamide, acetamide and urea which exhibit relatively high permeability coefficients. This is supported by the much higher concentration of mature FmdC in cells grown in continuous culture under amide or urea limitation than under methanol limitation (or in batch culture), since under these latter two conditions the amides and urea are present at high concentrations (up to approximately $20 \mathrm{mM}$ ) and can therefore enter the cell by simple diffusion alone at a rate fast enough to support the observed growth rate. It is also supported by the over- expression of mature FmdC during prolonged growth under formamide limitation, where any improvement in the permeability of the outer membrane to formamide would lead to increased 'biological fitness' (Dykhuizen \& Hartl, 1983) and hence be a major selective advantage.

The high concentration of the porin in cells grown under conditions where formamide $\left(M_{\mathrm{r}} 45\right)$, acetamide $\left(M_{\mathrm{r}} 59\right)$ or urea $\left(M_{r} 60\right)$ is the limiting nutrient, but not when methanol $\left(M_{\mathrm{r}} 32\right)$ is the limiting nutrient, suggests that it may act as a substrate-specific channel for compounds with the general formula $\left(\mathrm{R} . \mathrm{CO} \cdot \mathrm{NH}_{2}\right)$, rather than as a general pore for low $M_{r}$ substrates, i.e. more like LamB, Tsx, ScrY and various $P$. aeruginosa porins, than like OmpF, OmpA or PhoE (Nikaido, 1993, 1994; Schulz, 1993; Schirmer et al., 1995; Nieweg \& Bremer, 1997).

\section{ACKNOWLEDGEMENTS}

The authors are indebted to Dr Mark Carver and Professor W. J. Brammar for useful discussions, and to Dr K. Lilley for the N-terminal amino acid sequencing. N.R.W. and J.M. were supported by Collaborative Awards in Science and Engineering studentships (UK Science and Engineering Research Council) in collaboration with ZENECA Bio Products.

\section{REFERENCES}

Bradford, M. M. (1976). A rapid and sensitive method for the quantitation of microgram quantities of protein using the principle of protein-dye binding. Anal Biochem 72, 248-254.

Cowan, S. W., Schirmer, T., Rummel, G., Steiert, M., Pauptit, R. A., Jansonius, J. N. \& Rosenbusch, J.P. (1992). Crystal structures explain functional properties of two E. coli porins. Nature 358, 727-733.

Dixon, R. (1984). Tandem promotors determine regulation of the Klebsiella pneumoniae glutamine synthetase $(g \ln A)$ gene. Nucleic Acids Research 12, 7811-7830.

Duchene, M., Schweizer, A., Lottspeich, F., Krauss, G., Marget, M., Vogel, K., Von Specht, B. U. \& Domdey, H. (1988). Sequence and transcriptional start site of the Pseudomonas aeruginosa outer membrane porin protein F gene. J Bacteriol 170, 155-162.

Duffaud, G. D., Lehnhardt, S. K., March, P. E. \& Inouye, M. (1985). Structure and function of the signal peptide. Curr Top Membr Trans 24, 65-104.

Dykhuizen, D. E. \& Hartl, D. L. (1983). Selection in chemostats. Microbiol Rev 47, 150-168.

Goodwin, P. M. \& Anthony, C. (1995). The biosynthesis of periplasmic electron transport proteins in methylotrophic bacteria. Microbiology 141, 1051-1064.

Greenwood, J. A., Cornish, A. \& Jones, C. W. (1990). Bindingprotein-dependent lactose transport in Agrobacterium radiobacter. J Bacteriol 172, 1703-1710.

Jeanteur, D., Lakey, J. H. \& Pattus, F. (1991). The bacterial porin superfamily: sequence alignment and structure prediction. Mol Microbiol 5, 2153-2164.

Kreusch, A. \& Schulz, G. E. (1994). Refined structure of the porin from Rhodopseudomonas blastica. J Mol Biol 243, 891-905.

Kyte, J. \& Doolittle, R. F. (1982). A simple method for displaying the hydropathic character of a protein. J Mol Biol 157, 105-132.

Mahenthiralingam, E., Draper, P., Davies, E. O. \& Colston, M. J. (1993). Cloning and sequencing of the gene which encodes the 
highly inducible acetamidase of Mycobacterium smegmatis. $J$ Gen Microbiol 139, 575-583.

Merrick, M. J. (1988). Nitrogen assimilation by bacteria. Symp Soc Gen Microbiol 42, 331-361.

Nieweg, A. \& Bremer, E. (1997). The nucleoside-specific Tsx channel from the outer membrane of Salmonella typhimurium, Klebsiella pneumoniae and Enterobacter aerogenes; functional characterisation and DNA sequence analysis of the $t s x$ genes. Microbiology 143, 603-615.

Nikaido, H. (1993). Transport across the bacterial outer membrane. J Bioenerg Biomembr 25, 581-589.

Nikaido, H. (1994). Porins and specific diffusion channels in bacterial outer membranes. J Biol Chem 269, 3905-3908.

Nikaido, H. \& Vaara, M. (1985). Molecular basis of bacterial outer membrane permeability. Microbiol Rev 49, 1-32.

Rawling, E. G., Martin, N. L. \& Hancock, R. E. W. (1995). Epitope mapping of the Pseudomonas aeruginosa major outer membrane porin protein OprF. Infect Immun 63, 38-42.

Rost, B. \& Sander, C. (1993). Prediction of protein structure at better than $70 \%$ accuracy. J Mol Biol 232, 584-599.

Rost, B. \& Sander, C. (1994). Combining evolutionary information and neural networks to predict protein structure. Proteins 19, $55-72$.

Sambrook, J., Fritsch, E. F. \& Maniatis, T. (1989). Molecular Cloning: a Laboratory Manual, 2nd edn. Cold Spring Harbor, NY: Cold Spring Harbor Laboratory.
Schirmer, T., Keller, T. A., Wang, Y.-F. \& Rosenbusch, J. P. (1995). Structural basis for sugar translocation through maltoporin channels at $3.1 \AA$ resolution. Science $267,512-514$.

Schulz, G. E. (1993). Bacterial porins : structure and function. Curr Opin Cell Biol 5, 701-707.

Silman, N. J., Carver, M. A. \& Jones, C. W. (1989). Physiology of amidase production by Methylophilus methylotrophus: isolation of hyperactive strains using continuous culture. J Gen Microbiol 135, 3153-3164.

Struyve, M., Moons, M. \& Tommassen, J. (1991). Carboxyterminal phenylalanine is essential for the correct assembly of a bacterial outer-membrane protein. J Mol Biol 218, 141-148.

Wilson, S. A. \& Drew, R. E. (1991). Cloning and DNA sequence of amiC, a new gene regulating expression of the Pseudomonas aeruginosa aliphatic amidase, and purification of the amiC product. J Bacteriol 173, 4914-4921.

Wyborn, N. R., Scherr, D. J. \& Jones, C. W. (1994). Purification, properties and heterologous expression of formamidase from Methylophilus methylotrophus. Microbiology 140, 191-195.

Wyborn, N. R., Mills, J., Williams, S. G. \& Jones, C. W. (1996). Molecular characterisation of formamidase from Methylophilus methylotrophus. Eur J Biochem 240, 314-322.

Received 28 February 1997; revised 25 March 1997; accepted 26 March 1997. 